\title{
Apropriação territorial e o fenómeno da patrimonialização: o caso de Belém-Lisboa
}

\author{
Rafael H. Teixeira-da-Silva* \\ Universidade Federal de Juiz de Fora (Brasil)
}

\begin{abstract}
Resumo: Em grandes linhas, podemos dizer que o patrimônio diz respeito ao modo como uma sociedade se apropria do passado. Na contemporaneidade, este tende a ser visto, através da sua utilização, como um recurso cultural, político e econômico. É, neste contexto, marcado pelo ímpeto em preservar as marcas do passado, com sentido e significado para diferentes comunidades, que se desenvolve a presente investigação. Esta busca, precisamente, examinar as formas como o processo de patrimonialização tem contribuído para a produção do espaço e a sua apropriação pela população, conferindo-lhe um sentido de lugar. O desenvolvimento desta problemática realiza-se mediante um caso de estudo - a freguesia de Santa Maria de Belém (Lisboa), dotada de um importante conjunto arquitetônico. Nesse sentido, foi realizada uma investigação de cariz etnográfico, com recurso a métodos de pesquisa qualitativos. Através da pesquisa realizada foi possível apreender os espaços mais significativos na vida de bairro dos entrevistados, que buscam manter os seus costumes e práticas tradicionais, ao mesmo tempo em que novos hábitos e vivências são criados pelos processos de patrimonialização e turistificação do lugar.
\end{abstract}

Palavras-chave: Belém; Patrimônio Cultural; Patrimonialização; Apropriação Territorial.

Territorial appropriation and the heritagization phenomenon: the case of Belém-Lisbon.

Abstract: Broadly speaking, we may say that heritage relates to the way a society appropriates the past. In contemporary times, heritage has the propensity to be seen through its use as a cultural, political and economic resource. It is in this context, marked by the urge to preserve the marks of the past with meaning and significance for different communities, that the present investigation is developed. This essay seeks to examine the ways in which the heritagization process contributes to the production of space and its appropriation by the population, giving it a sense of place. For the development of this work, the chosen area of study was the neighborhood of Santa Maria de Belém-Lisbon. In order to examine how the phenomenon of heritagization reflects itself in the appropriations of Belém, an ethnographic-oriented research was conducted, using qualitative research methods. In this sense, the research is based on semi-structured interviews and participant observation. Through the survey, it was possible to identify the most significant spaces in the neighborhood life of respondents who seek to maintain their traditional customs and practices, while new habits and experiences have been created by the heritagization processes and the touristification of the place.

Keywords: Belém; Cultural Heritage; Heritagization; Territorial Appropriation.

\section{Introdução}

Independente de ser celebrado ou repudiado, o passado é onipresente. As memórias, os artefatos, as edificações e os lugares, impregnam a experiência humana. Enquanto os traços pessoais imbuídos nestes elementos vão sucumbindo ao tempo, os aspectos coletivos dos mesmos mantêm-se infindáveis. Cada dia mais, os elementos do passado são deliberadamente chamados à memória. A contemporaneidade é marcada pela vontade e pelo ímpeto em preservar, sobretudo, devido ao rápido desenvolvimento e às vertiginosas mudanças que marcam as sociedades atuais e acabam por abalar seu legado cultural

Universidade Federal de Juiz de Fora (Brasil); E-mail: rafahts@hotmail.com 
(Lowenthal, 1985). Atualmente, além do fato de contribuir para as identidades culturais e para o bem-estar social, o próprio ato de preservar se tornou um dos principais modos de apreciar o passado. É neste contexto, que o patrimônio cultural apresenta-se como o uso contemporâneo do passado, no qual o mesmo é construído e definido pelas circunstâncias atuais (Graham et al., 2000).

O que já foi um passado diletante apresenta-se, atualmente, como uma interminável e implacável cruzada pelo patrimônio, fato que tem consequências imediatas na apropriação do território urbano. Somada à tendência pela adoção de uma abordagem padronizada sobre o patrimônio - patrimonialização - encontra-se neste entrelaçar, o tema central do presente trabalho. É rigorosamente, nas articulações entre as apropriações do território urbano e o processo de patrimonialização, que o artigo será compreendido. Nesse sentido, para a realização do estudo de caso da pesquisa foi escolhida a Freguesia de Santa Maria de Belém-Lisboa, por ser uma área que possui um rico patrimônio arquitetônico e um grande fluxo de pessoas, que são atraídas por este patrimônio, o que leva a uma relação dialética de ressignificação territorial, paisagística e simbólica.

Fundamentalmente delimitado como um lugar de memória, para o melhor conhecimento das características encontradas em Belém, realizou-se visitas exploratórias pela freguesia e, ainda, algumas leituras consideradas essenciais para a apreensão da área. A partir desta aproximação, foi possível tomar como ponto de partida a forma como a patrimonialização contribui para a produção e apropriação de Belém. Tendo este fio condutor como princípio, será questionado, essencialmente, o que é o processo de patrimonialização e quais são as formas de apropriação criadas pelos habitantes locais, face a este fenômeno.

No sentido de desenvolver a presente pesquisa, o processo de patrimonialização será salientado como um fator fundamental na produção de Belém. A investigação será baseada em uma metodologia qualitativa, que permite um conjunto de vantagens, no que concerne à compreensão aprofundada sobre os hábitos e a vida cotidiana dos habitantes locais - fato essencial para a apreensão dos espaços mais significativos na vida de bairro dos inquiridos. Deve ser lembrado que a utilização de métodos qualitativos, neste caso, de entrevistas semiestruturadas e observação participante, não visa ser representativa, mas sim ser uma importante ferramenta na compreensão da forma como as pessoas vivenciam e dão sentido às suas vidas.

\section{Concepções do patrimônio cultural e o processo de patrimonialização}

Na lexicografia portuguesa, a designação "patrimônio" começa a ser aplicada e vinculada aos valores do legado cultural somente no último quartel do século XIX (Custódio, 2010:96). Neste âmbito, a palavra patrimônio foi inicialmente definida na língua portuguesa como herança paterna e bens familiares. Posteriormente passou a ser referenciada como o conjunto de bens culturais ou naturais de valor reconhecido por determinada localidade, região, país ou para a humanidade, que ao ser inventariado e registrado, deve ser preservado para o usufruto de todos os cidadãos. É interessante ressaltar que algumas obras ${ }^{1}$ fazem menção à Lista de Patrimônio Mundial da UNESCO (United Nations Educational, Scientific and Cultural Organization) e à ideia de posse coletiva sobre o patrimônio como parte do exercício da cidadania.

Ao utilizar esta definição do conceito de patrimônio como ponto de partida, é importante assinalar uma grande lacuna deixada em branco, ao passar da simples ideia de herança e bens familiares para a noção de posse coletiva, exercício da cidadania e Patrimônio Mundial.

Como demonstrado pelo emérito professor e pesquisador em Geografia, David Lowenthal (1998, p. 3-4), patrimoine (em francês), patrimony ou heritage (em inglês), expandiu sua definição de simples bens herdados do passado, e passou a abranger heranças deixadas por antepassados e legados culturais em geral. Lowenthal (1998) sugere que devido a esses fatores - e também por acreditar que ao se realçar tradições de comunidades específicas, faz com que aumente a autoestima e o sentimento de identidade destas comunidades -, a utilização de elementos do passado varia em cada sociedade.

Nesse sentido, Brito Henriques (2003:195) utiliza alguns adjetivos para expressar de forma mais categórica os elementos envolvidos na fundamentação do conceito de patrimônio. $\mathrm{O}$ autor faz a distinção entre patrimônio familiar, patrimônio genético, patrimônio natural, e patrimônio cultural (bens materiais ou imateriais, de uma sociedade ou grupo, herdado de gerações prévias e transmitido às gerações vindouras, relacionados à identificação dos indivíduos com sua comunidade). Sendo que, neste último, reside o nosso maior interesse, pelo fato do patrimônio histórico-arquitetônico - nosso foco no presente trabalho - ser parte constituinte do patrimônio cultural.

Além de D. Lowenthal e E. Brito Henriques, outros autores que demonstram algumas preocupações da Geografia com o patrimônio são Graham, Ashworth e Tunbridge (2000). Tais investigadores se interessaram pelas formas como o passado é lembrado e representado, tanto no âmbito oficial quanto no popular, e os efeitos geográficos que estes fatos têm no presente. Graham et al. (2000) acreditam 
que o fenômeno patrimonial é intrinsecamente espacial e que sua classificação como domínio dotado de significado atesta o mesmo como um campo de conflito social. Deve-se ressaltar que os autores exteriorizam o patrimônio como um bem cultural e econômico, que acaba por multiplicar seu uso e consumo, originando em alguns casos conflitos entre diferentes grupos e seus interesses.

Para que seja possível exercer uma reflexão a respeito do tema, é imprescindível fazer menção ao trabalho desenvolvido pela historiadora das teorias e formas urbanas e arquitetônicas Françoise Choay (2001), em sua obra A Alegoria do Patrimônio. Neste livro a autora referência a procedência essencialmente associada às estruturas familiares, econômicas e jurídicas do patrimônio, mas vai muito além destes componentes.

Desde seu advento, o tema vem passando por inúmeras mudanças constantemente influenciadas pelos ideais de cada época. Pode-se afirmar que "[...] não há coincidência entre o entendimento acerca do que é património, por parte de um humanista do século XVI, [...] por um iluminista do Século das Luzes, de um romântico oitocentista ou de um de nossos contemporâneos", sendo que "[...] cada época reflecte parte de si própria, na forma como perspectiva e cuida do seu património" (Mendes, 2009:10). Corolário ao pensamento exposto, Ashworth (1994) identifica um deslocamento patrimonial na contemporaneidade, que passa então a ser orientado pelo mercado. Tal afirmação se baseia na seleção contemporânea de produtos de acordo com a demanda dos consumidores, sendo que, neste contexto, o patrimônio se apresenta como "[...] a contemporary commodity purposefully created to satisfy contemporary consumption" (Ashworth 1994: 16).

O movimento para a criação de um patrimônio mundial foi promovido pelas Nações Unidas através da UNESCO, no cenário pós Segunda Guerra de manutenção da segurança internacional. A UNESCO, em conjunto com sua subsidiária ICOMOS (International Council of Monuments and Sites), produziu códigos de práticas ideais e organizou uma gama de ações baseadas no estabelecimento de um conjunto de leis internacionais sobre as propriedades culturais. Dada a conjuntura apresentada, difundiu-se a presunção da necessidade de existência de um patrimônio mundial como propriedade coletiva de todos os povos.

As ações que visam à construção de um patrimônio mundial desenvolvidas por organizações internacionais estão alicerçadas basicamente em três conjuntos de elementos. $\mathrm{O}$ primeiro argumento é baseado na ideia de que, desde seus primórdios, a produção do patrimônio foi significantemente influenciada por movimentos culturais e questões estéticas que estavam muito além das fronteiras políticas. Em segundo lugar, houve nas últimas décadas uma considerável propagação da preocupação global sobre o resguardo do patrimônio. Por fim, o movimento de maior expressão, no que diz respeito à demanda por um patrimônio mundial, parte da perspectiva dos consumidores que frequentam monumentos, museus, sítios e cidades históricas, e exercem a reivindicação pelo acesso global de forma ativa sobre este patrimônio. Algumas questões retiradas da reivindicação por um patrimônio mundial são: se há realmente a propriedade comum sobre a atividade artística humana voltada para o enriquecimento pessoal, então todos deveriam contribuir para seu amparo e proteção; e, sobretudo, como falar em um patrimônio mundial se o mesmo continua subordinado à soberania dos governos nacionais e às estratégias de gestão local (Graham et al., 2000).

Deste modo, considera-se que a patrimonialização, ou heritagization, está pautada na adoção de abordagens, ditas exemplares, impulsionadas pelo intercâmbio de filosofias e técnicas utilizadas nas chamadas "melhores práticas", que já obtiveram sucesso outrora (Graham et al., 2000:237). Ao utilizar um padrão que tenha obtido êxito em outros lugares, os riscos assumidos seriam reduzidos. O emprego destas práticas por corporações que são responsáveis pelo desenvolvimento de projetos de intervenção patrimonial, acaba por incentivar a seleção homogênea de materiais, mobiliário urbano e sinalização, produzindo um estilo internacional do patrimônio.

Esta é a questão chave sobre o assunto, pois é o ponto de convergência das diferentes teorias sobre a patrimonialização. A partir da verticalização - que seria a ligação de pontos separados e distantes no espaço, conectados por processos sociais que garantem a atuação global da sociedade e da economia (Santos, 1994:16; 2006:192) - das relações sociais e dos lugares, ocorre o processo de patrimonialização dos bens culturais, que passam a conter características e tendências de apropriações globais.

O que deve ser levado em consideração é que houve uma padronização das formas e da abordagem patrimonial, resultando numa homogeneização dos lugares e uma redução da diversidade local. Isso deve-se sobretudo: 1) ao intercâmbio e padronização das práticas profissionais relacionadas com o patrimônio (arquitetos, construtores, planejadores); 2) à influência de instituições internacionais, que tendem a minimizar os riscos ao repetir modelos que já obtiveram sucesso em outros lugares; 3) à criação de um catálogo patrimonial de mobiliário urbano; 4 ) à mercantilização da história, da cultura e dos costumes locais, que acaba por adaptar tais atributos, modificando comportamentos e estilos de vida (Graham et al., 2000). Revelados os elementos essenciais do processo de patrimonialização, é fundamental, como ressalta Luchiari (2005), voltar a atenção ao conteúdo que refuncionaliza e atribui de novos valores o patrimônio, buscando a compreensão dos distintos usos deste patrimônio e das práticas que produzem territorialidades excludentes. 


\section{Caracterização de Belém}

A Freguesia de Santa Maria de Belém (Figura 1), localizada na faixa ocidental da cidade de Lisboa, nasceu do sítio do Restelo. A freguesia possui uma área de $2102 \mathrm{~km}^{2}$, e de acordo com o último recenseamento realizado pelo Instituto Nacional de Estatística (INE), em 2011, tinha à data 8.546 residentes e 1.999 edifícios.

Com base no estudo realizado por Aquilino Machado (2006), foi possível estabelecer quatro momentos relevantes no processo de produção de Belém: 1) A gênese do local e o período quinhentista; 2) O pós-terremoto de 1755; 3) A Exposição do Mundo Português (1940); e, 4) A intitulação do patrimônio mundial e o processo de patrimonialização.

É neste contexto que, no início da década de 1980, emerge a dinamização da área e, em 1983, os monumentos do Mosteiro dos Jerônimos e a Torre de Belém são inseridos na lista de patrimônio mundial da UNESCO${ }^{2}$. A área protegida fica localizada na freguesia de Santa Maria de Belém, concelho de Lisboa, e possui uma extensão de 103 ha.

Figura 1: Freguesia de Santa Maria de Belém

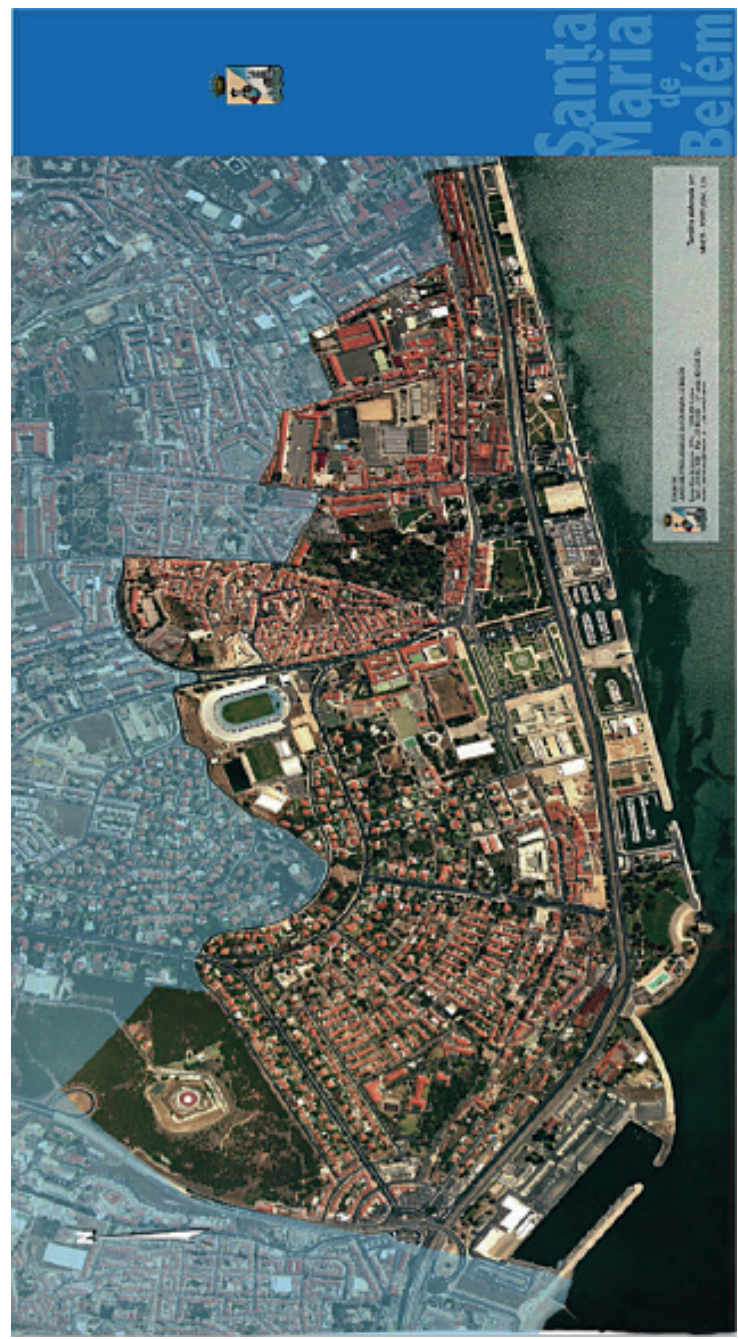

Fonte: http://www.jfelem.pt/index.php?option=com_content\&view=article\&id=84\&Itemid=108. 


\section{Discussão dos Resultados}

O estudo empírico aplicado ao presente trabalho foi realizado na Freguesia de Santa Maria de Belém durante os meses de abril e maio de 2013. Foram executadas 30 entrevistas com residentes locais. $\mathrm{O}$ método utilizado para recrutar os entrevistados foi o "snowball"3. Com o objetivo de compor um grupo de entrevistados de forma integrada, foram inquiridos 15 mulheres (50\%) e 15 homens (50\%), com idade igual ou superior a 21 anos, com o objetivo principal de abranger uma faixa etária ampla, mas mantendo o foco naqueles que possuam uma opinião formada sobre os assuntos tratados.

Considerando, em primeira instância, que as entrevistas semiestruturadas não visam ser representativas, mas sim um instrumento na compreensão aprofundada sobre a forma como as pessoas vivenciam o bairro, que o roteiro de entrevista foi estruturado em cinco seções. De modo geral, as perguntas abarcam os motivos pelos quais as pessoas moram em Belém, a forma como estas se apropriam do espaço, quais são suas vivências dentro do bairro, se possuem redes de amizades, qual o grau de apego com o sítio e como percebem o patrimônio e o turismo na freguesia.

Com o intuito de compreender, em um primeiro plano, o grau de enraizamento dos residentes de Belém com o local em si, questionou-se nas entrevistas semiestruturadas o período que os inquiridos residem na freguesia. Essa questão permitiu identificar que treze entrevistados sempre viveram em Belém, ou mudaram-se para a área nos primeiros anos de vida. Entre os restantes inquiridos que vieram de outras áreas, destaca-se um grupo de sete pessoas que se mudou por motivos familiares (relativamente por motivo matrimonial e pelo fato de outros integrantes da família residirem na área) e outros sete devido a trabalho ou estudo, e por fim três inquiridos que relacionaram a mudança com a tranquilidade e as condições de habitação no bairro.

É interessante ressaltar que todos os inquiridos mencionaram gostar de viver em Belém. $\mathrm{O}$ alto grau de satisfação dos residentes, muitas vezes, está relacionado ao forte enraizamento emocional com o lugar, advindo do longo período de residência no local que se reflete no contentamento unânime revelado. Mesmo entre o total de pessoas que vieram de outras localidades (17) é comum a justificativa da mudança estar relacionada com a vontade e o desejo de residir neste sítio.

Adoro! É o melhor sítio do mundo para se viver. [...] Há o rio, o sol e a natureza. ${ }^{4}$

Gosto muito. Decidi morar em Belém mesmo por escolha, não foi porque calhou. ${ }^{5}$

Os moradores, quando indagados sobre os motivos que mais lhes agradam em Belém, tendem a vincular os seus sentimentos e impressões com alguns aspectos e características do lugar. Tal envolvimento, individual e coletivo, nos permite compreender o contexto social no qual estão inseridos e o processo de identificação que os mesmos mantêm com o sítio.

Tendo em conta, como foi mencionado anteriormente, que o sentido de lugar é natural - a busca por um lugar o qual pertencemos é algo da natureza humana e mesmo sugerido como um instinto territorial -, construído por estruturas de poder e faz parte das construções de identidade (Rose, 1995), almejou-se apreender as dinâmicas no enlace entre identidade e sentido de lugar, para compreender o processo de apropriação decorrente em Belém. Reitera-se aqui o argumento a favor da estratificação múltipla de sentimentos de pertença híbridos, expressos nas palavras a seguir:

No meu caso eu identifico-me com tudo. Olha, tem a parte cultural, artística. Todos estes monumentos têm uma carga artística e histórica muito forte, então, eu como estudei artes e pintura identifico-me com isto. Tem esta igreja (dos Jerônimos) monumental. Também me identifico com isto, com a fé. Mais os espaços de lazer, pois gosto de fazer desporto, também me identifico com isto. Portanto, tem aqui tudo. Espaços verdes, de certa forma uma paisagem bonita, pois temos aqui o rio, podemos ver a torre de Belém e o Cristo Rei lá no alto. A torre de Belém é belíssima ali no rio, então é um espaço que tem tudo. Cultural, religioso, paisagístico, desportivo e de lazer, portanto, identifico-me com tudo. ${ }^{6}$

É possível visualizar neste trecho o dinamismo do sentido de lugar espelhado na paisagem patrimonial de Belém. O patrimônio de Belém está repleto de múltiplos significados e sentidos, o que impede de compreender o mesmo como uma representação hegemônica de uma ideologia. O Mosteiro dos Jerônimos, como será contemplado ao longo desta parte, é reconhecido pelos moradores como um sítio histórico e religioso, mas também como um espaço cultural e, mais importante, como o lugar que faz parte da 
vida dos autóctones. É o sítio no qual frequentam as cerimônias religiosas, no qual foram crismados, casaram e principalmente onde se encontram com familiares e amigos.

Desse modo, foram representados (Figura 2) os elementos, características e lugares com que os habitantes mais se identificam. Como pode ser visto, pois o número de vezes que a palavra foi mencionada é contemplado pela sua dimensão na figura, O Mosteiro dos Jerônimos aparece como o elemento de maior identificação na freguesia. Dos trinta entrevistados, treze mencionaram identificar-se com o Mosteiro dos Jerônimos. Além do Mosteiro, o discurso dos entrevistados enfatizou um universo heterogêneo de elementos que compreendem a Torre de Belém, o bairro de Belém, o conjunto de monumentos, a "rua das lojas", os espaços culturais e de lazer, as áreas verdes e o rio Tejo.

Figura 2: Representação dos elementos com que os habitantes de Belém mais se identificam.

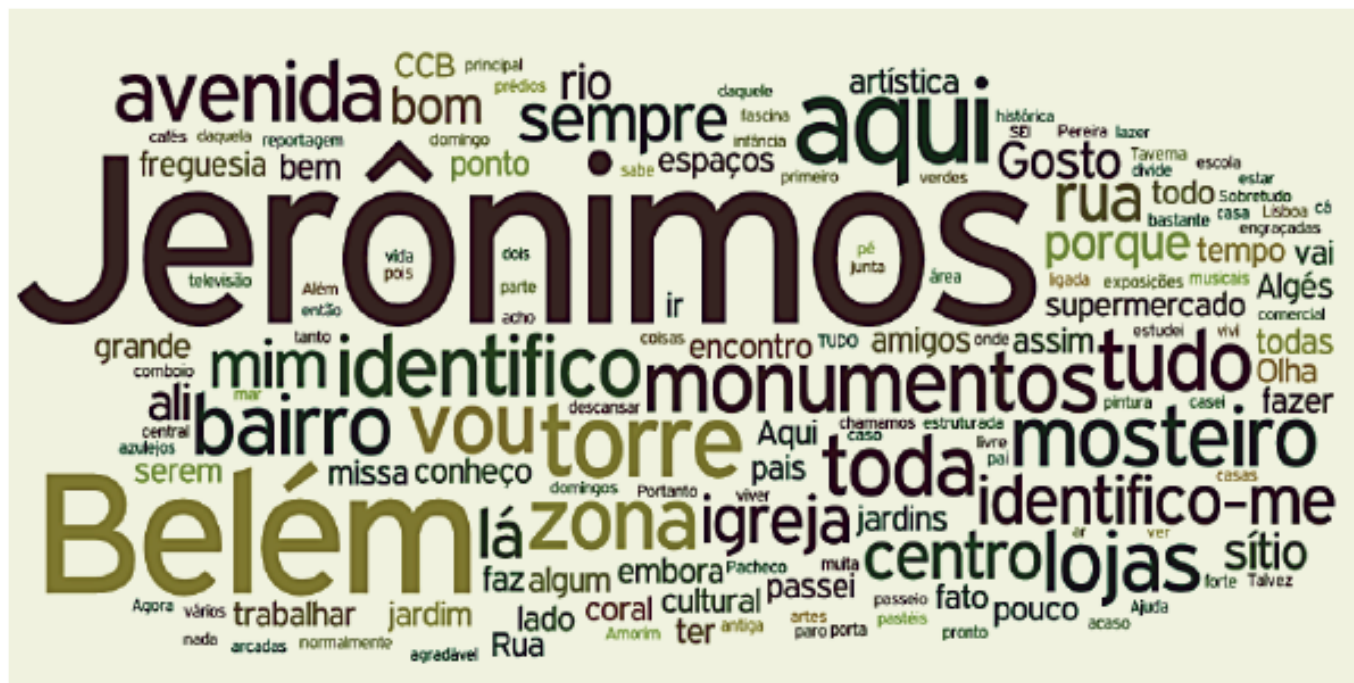

Fonte: Elaborado pelo autor

Concordamos com Lobo de Carvalho (2009, p. 164) ao acentuar o Mosteiro como um dos exemplares mais importantes do aglomerado patrimonial e turístico da cidade de Lisboa. Entretanto, pondera-se que ao contrário do que Lobo de Carvalho (2009) sustenta, a área de influência do Mosteiro dos Jerônimos vai além do que seria a "Zona Monumental de Belém", pois o mesmo não representa somente um sítio de oferta cultural e turística, como também é o lugar onde as pessoas que vivem na freguesia fazem suas vidas. Devido ao fato do Mosteiro dos Jerônimos ser um sítio de altíssimo valor arquitetônico e cultural, de acontecimentos históricos relevantes, onde ilustres personagens do país marcaram presença, tais fatos levam a integração do edifício na identidade dos habitantes locais. Assim, ao admitir que existam duas formas de organizar as lembranças, ora agrupadas em torno de uma pessoa (memória individual), ora distribuídas no interior de uma sociedade (memória coletiva), as duas ao se cruzarem transformam uma parte do lugar à sua imagem (Halbwachs, 1990). Simultaneamente, este conjunto de memórias se articula e atua nas construções simbólicas que se mantém entre os habitantes locais e o lugar.

No sentido de confirmar a alegação de que o processo de identificação das pessoas com estes lugares de memória (Nora, 1993) é baseado na presença de características únicas apresentadas por estes, fica nítido na situação abaixo que o modo como os indivíduos se definem é representado por certas qualidades do lugar com que se identificam. Apesar dos indivíduos dispensarem uma atenção desigual aos aspectos materiais de Belém, cada característica, cada particularidade deste lugar, possui um sentido que é inteligível somente para os habitantes locais: 
Identifico-me muito com esta avenida grande que vai até Algés. Está a ver essa avenida grande que faz assim e depois continua, vai até Algés. Porque são duas, esta aqui a princípio é a Avenida das Descobertas e a outra que continua é a Vasco da Gama. Depois a outra que continua é a rua que vivem os meus pais. Por isso, mal chego cá acima já sinto que eu estou em casa. E eu estudei neste liceu, estudei no colégio em frente, por isso sinto que é a minha zona. ${ }^{7}$

Identifico-me talvez com a Avenida da Torre de Belém, porque embora não seja a avenida principal do comércio é uma avenida central no bairro. O que divide um pouco os vários lados do bairro. Até porque lá é o supermercado, e o supermercado é sempre o centro do bairro, de qualquer bairro. ${ }^{8}$

É interessante ressaltar que neste último relato (entrevistado $\mathrm{n}^{\circ} 26$ ), constata-se uma importante evidência da patrimonialização na produção de Belém. O traço da Avenida da Torre de Belém (Figura 3), elaborado durante o Estado Novo, teve precisamente a finalidade de concentrar o foco na Torre de Belém, fato que permeia as lembranças e mesmo a construção de identidade de alguns habitantes, como é o caso deste entrevistado. Ao explorar a forma como o entrevistado $\mathrm{n}^{\circ} 26$ compreende e expressa, com eloquência, a centralidade que o supermercado possui na freguesia, evidencia-se como este lugar é significativo na vida de bairro e no cruzamento entre as diferentes camadas sociais do bairro.

Ao voltar a atenção para as relações que conferem uma ligação entre indivíduos e lugares, o patrimônio possui um papel crucial na concepção dos sentimentos de pertença, que ocorrem por meio da inserção de memórias coletivas no território. Como ficou constatado nas entrevistas e durante a observação participante, a memória coletiva e o patrimônio possuem grande importância na construção simbólica de Belém, e, por conseguinte, nos sentimentos de pertença dos residentes. Tais características passam a fazer parte das práticas do dia-a-dia dos moradores, pois são incorporadas pelas pessoas com quem compartilham tempos e espaços cotidianos. No enlace entre as pessoas - e as suas memórias - e o patrimônio localizado em Belém, os habitantes deixam suas marcas no sítio, mas o percurso contrário também se efetua.

\section{Figura 3: Avenida da Torre de Belém.}

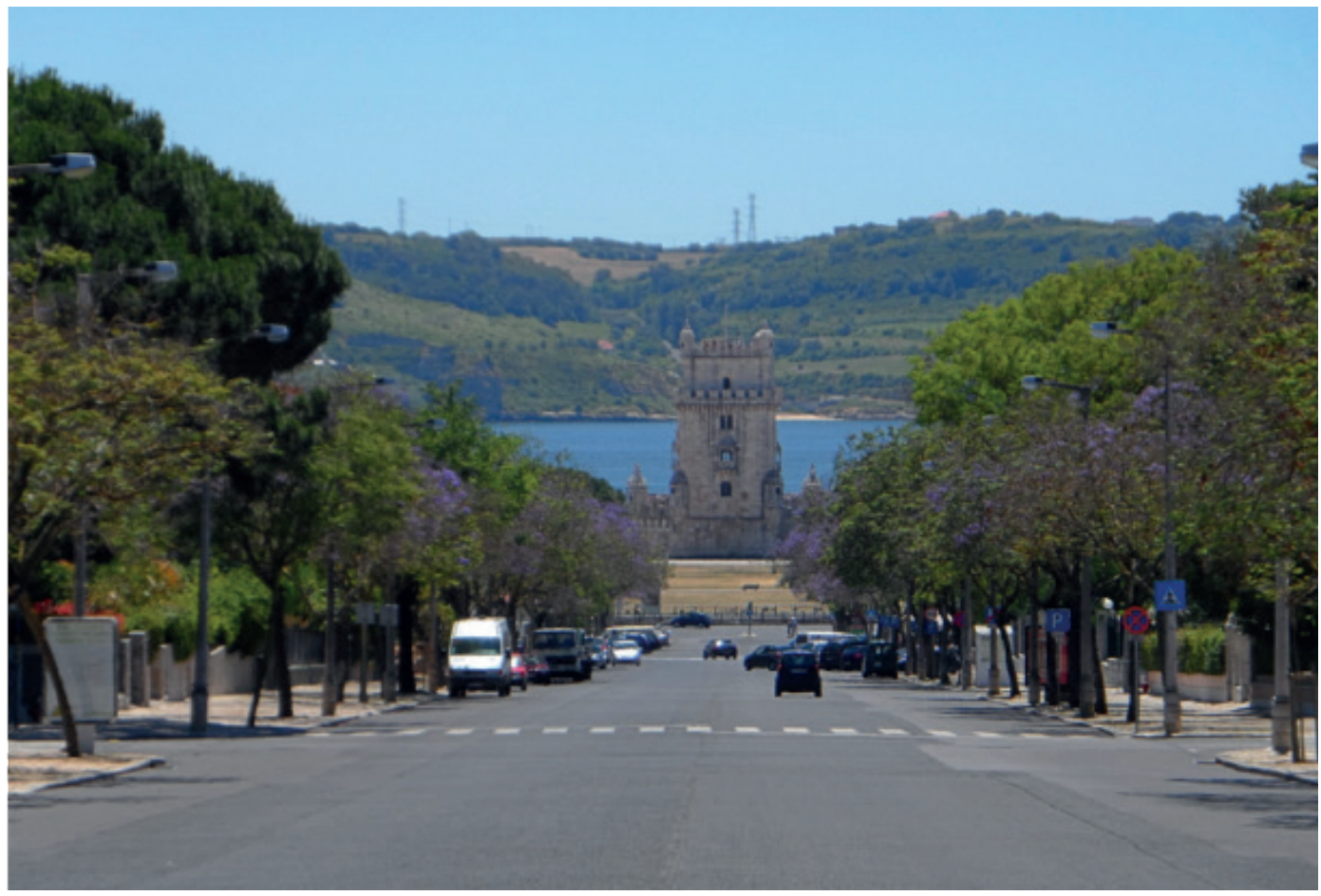

Fonte: Arquivo do autor. 
Contudo, apesar do reconhecimento de tais sentimentos e identidade urbana, Belém é um espaço em constante mudança por ser produto de processos sociais, culturais e políticos. Ao abarcar uma esfera concreta e uma esfera simbólica, as espacialidades sociais inseridas em Belém são aqui concebidas no âmbito de suas complexas interações. Portanto, considera-se que a parte histórica de Belém e suas formas são componentes ativas no processo de refuncionalização territorial gerada pela patrimonialização.

É incontestável que o grande fluxo de turistas na zona de Belém traz inúmeros benefícios econômicos, especialmente no contexto de crise econômica em que o país se encontra. Entretanto, seria importante que os benefícios diretos e indiretos gerados pela receita turística - restritos aos setores de comércio e restauração, e aos monumentos - não se traduzam apenas em benefícios econômicos, mas também em melhoria das condições de vida em Belém. Porém, como é perceptível no discurso de alguns moradores, a grande demanda da oferta turística levou à supressão de algum comércio mais orientado para as necessidades dos habitantes:

Antigamente havia muito comércio, era mais diversificado com muitas mercearias, vivendas e de artigos pessoais e para casa. Depois derrubaram tudo para construir restaurantes, cafés e vendas de artigos turísticos. Olha, não há mercearias, não há supermercados. Só há farmácia. Temos muitas pastelarias, temos muitos restaurantes. Isto é uma zona turística. Quer dizer, nós aqui num sítio tão bonito e não temos muita coisa (necessária para o cotidiano). Eu sinto falta, como moradora. ${ }^{9}$

Segundo a opinião dos moradores, encontram-se três conjuntos de obstáculos na vivência de locais específicos dentro da freguesia, como o exemplo do Jardim Botânico Tropical, citado por alguns entrevistados. Um relacionado com a privação da entrada a um espaço público ao qual dispunham previamente de livre acesso. Já o segundo, está associado ao constrangimento e à perturbação que o volumoso fluxo turístico tem sobre o lugar. Há ainda um terceiro conjunto de obstáculos à apropriação dos moradores, que está vinculado à realização de atividades e eventos que muitas vezes são voltados para a população que não reside em Belém. Com base na observação participante, foi possível verificar que durante a realização de eventos e cerimônias a população de Belém tem sua circulação prejudicada.

Como constatado ao longo do texto, Belém é um sítio que vem sendo transformado pelas verticalidades (Santos, 1994; 2006) que se repercutem em reformulações arquitetônicas e nas práticas sociais. Fato que acarreta a produção de novas territorialidades descomprometidas com a área e com as populações locais. As territorialidades excludentes são estendidas para alguns espaços da freguesia, de modo que, a investigação demonstra que, muitas vezes, a constituição das redes sociais estão relacionadas com a classe social, a faixa etária e as origens culturais dos entrevistados.

No entanto, acredita-se que mesmo com os obstáculos encontrados no dia-a-dia, os habitantes de Belém não se desligaram totalmente das suas redes de amizades e dos lugares significativos para a construção de suas identidades. Nesse sentido, a análise visou superar os termos superficiais encontrados na dicotomia entre "lugar turístico" vs. "aldeia dentro da cidade" ${ }^{\text {. }}$ Mesmo com o grande desenvolvimento turístico e cultural, os belenenses continuam, por meio de suas práticas espaciais, a utilizar e a atribuir significados ao lugar. Contra todas as previsões, alguns espaços de Belém continuam a ser apropriados e reivindicados por um pequeno número de pessoas, por meio da manutenção ativa de atividades e costumes tradicionais da zona.

Eu pelo menos, quando passeio e ando, consigo imaginar todos os costumes desde o início até agora. Inclusive há coisas que ainda não se perderam. É preciso escavar muito para se encontrar, mas que ainda existem. Como o lado 'pescatório' que toda esta zona tem. Hoje em dia está muito mais associado à pesca desportiva, mas há quem ainda viva da pesca porque eu conheço algumas destas pessoas que partem de manhã no seu barquinho e vão à pesca. Voltam com peixe, vendem o peixe, cozinham o peixe, comem o peixe, por ai fora. E o lado mais artesanal, que está provavelmente ligado ao comércio, com as pequenas feiras que existem mensalmente. Não sei se é no primeiro domingo ou no segundo domingo do mês. Mas há este lado artesão, porque se vende muita coisa, muito artesanato. ${ }^{11}$

Já com relação a outro tipo de atividade realizada no Mosteiro dos Jerônimos, destaca-se, em particular, o discurso de um entrevistado sobre a apropriação da zona mencionada, notavelmente, por transgredir os "usos habituais" deste sítio. Ao serem realizadas peças de teatro com estudantes da freguesia nos claustros do Mosteiro, são abertas novas perspectivas sobre o mesmo. Representada por uma ação educativa, de exploração física, que ultrapassa os limites convencionais deste sítio, esta nova ótica incorporada pelos estudantes contribui para a configuração da identidade cultural dos mesmos. 
Eu faço todos os anos, sazonalmente, de novembro a abril, do início de novembro a final de abril, teatro para crianças, para escolas nos Jerônimos, nos claustros dos Jerônimos. De fato dai que talvez venha minha afronta com os turistas porque para trabalhar tenho que passar por um mar deles (turistas). Eu entro mesmo dentro dos Jerônimos e faço teatro dentro do edifício antigo. Tem muito a ver com Gil Vicente, tem muito a ver com o que Gil Vicente representou para o teatro, com o que representou para os Jerônimos. Tem uma participação ativa na parte dos monumentos, na parte histórica, está diretamente ligada a mim. Não só faço teatro nos Jerônimos, como faço teatro "Vicentino", que é de uma determinada época, estamos a falar de século XVI, num espaço onde o próprio autor desempenhou algumas encenações e alguns espetáculos naquele próprio edifício, para Reis. Fez aquilo para a Rainha D. Leonor, fez vários "Autos" e como trabalho neste espaço e como trabalho na área educacional, acabo por ser um professor, digamos, lúdico na disciplina de português. Porque o "Auto da Barca do Inferno", que é a peça que faço, faz parte da matéria dada no $9^{\circ}$ ano. ${ }^{12}$

A respeito dos espaços considerados mais significativos na vivência de bairro dos entrevistados, para além das respostas que já eram esperadas - que compreendem os diversos jardins da freguesia, a área do Mosteiro dos Jerônimos, a Torre de Belém e o Centro Cultural de Belém - um outro sítio sublinhado recorrentemente é a Rua Duarte Pacheco Pereira. Conhecida pelos moradores como a 'Rua das Lojas', esta via pode ser considerada o centro comercial, gastronômico, de lazer e de serviços, no qual a grande maioria da população faz sua vida de bairro.

Tendo em vista que as territorialidades referem-se à produção e reprodução de parcelas espaciais, que não se restringem a centralizar o convívio, mas também acentuam e intensificam suas delimitações (Soja, 1989), tais práticas vão sendo tecidas no entrelaçar dos itinerários percorridos por espaços específicos, como é o caso da "Rua das Lojas". Talvez pelo fato desta via estar localizada no interior do bairro e não ficar muito exposta aos outsiders ${ }^{13}$, este espaço é o que melhor exemplifica a apropriação simbólica consumada pelos habitantes de Belém. Devido aos laços de identidades sociais aqui construídos, verifica-se o fortalecimento dos sentimentos de pertença dos locais, que reivindicam e desfrutam desta zona nos seus usos cotidianos.

O mesmo princípio aplicado à "Rua das Lojas" deve ser referido quando analisamos a realização da "Festa dos Vizinhos". Este acontecimento é uma reunião informal dos moradores de Belém, organizado de modo conjunto entre os próprios habitantes do bairro e a Junta de Freguesia de Santa Maria de Belém, que possui o intuito de agregar as pessoas que residem na área. Embora tenham encontrado algumas dificuldades em angariar fundos para a realização dos eventos mais recentes, identifica-se o empenho para a preparação da festa por parte de alguns moradores, e ainda uma grande vontade em participar, por parte de outros.

\section{Considerações Finais}

A partir do estudo realizado, algumas considerações finais devem ser elaboradas sobre as principais ideias expressas na presente pesquisa. A investigação destinou-se a apresentar a temática da patrimonialização como uma análise coerente centrada em Belém. Nesse sentido, o patrimônio foi evidenciado como o uso contemporâneo do passado, construído e delimitado pela atual conjuntura. Como afirmado anteriormente, este trabalho não teve como objetivo obter resultados conclusivos ou representativos, mas sim buscar compreender importantes questões sobre aspectos relevantes ligados ao processo de patrimonialização, à forma como este intervém na produção do espaço urbano e influencia a apropriação do espaço em Belém.

Entre os principais impactos que o fenômeno da patrimonialização exerce na produção de Belém, é imperativo a menção às transformações no que concerne a composição do comércio local, a modernização urbana de algumas áreas da freguesia, o cuidado estético com sítios turísticos, e mesmo a realização de atividades e eventos que, muitas vezes, não são voltados para a população local. Constata-se que, com a inserção de novas práticas espaciais em Belém, houve certa tendência de destradicionalização da área. A interrupção de um desenvolvimento natural do bairro e a redefinição de vocações tradicionais, são fatores de influência excepcional no itinerário percorrido por este espaço. Tais fatores são retratados nos sentidos de lugar e nas apropriações dos habitantes de Belém.

Devido ao fato de Belém ser inerentemente um lugar de memória, a importância deste enquanto núcleo de sentimentos pessoais é reforçada pelo desenvolvimento de laços afetivos, ou seja, dos sentimentos de pertença dos habitantes locais em relação ao território. Os resultados adquiridos a partir da análise 
empírica evidenciaram que o elo que alguns moradores possuem com o lugar é devidamente complexo, e que o patrimônio permanece como um componente crítico na construção das identidades. O valor dos significados que estes habitantes atribuem a cada local é estabelecido por meio dos espaços vividos no bairro.

Desse modo, buscou-se compreender como os habitantes tornam próprio e adaptam o lugar, levando em consideração que a apropriação não pode ser entendida independentemente dos ritmos e do tempo de vida. Por estes motivos, as apropriações dos habitantes de Belém foram apreendidas em três níveis. Primeiramente foram identificadas apropriações pretéritas, em segundo lugar, observou-se a presença de territorialidades excludentes e de algumas barreiras à utilização de alguns sítios. Por último, foram classificadas as apropriações efetivas que estão relacionadas tanto com atividades tradicionais, quanto com a criação de novas formas de utilizar o lugar.

Com base nestas ferramentas, ficou constatada a apropriação de vários espaços dentro da freguesia, onde os belenenses, por meio de suas práticas espaciais, continuam a utilizar e atribuir significados ao lugar. A população residente entrevistada, de modo geral, revela distintas formas de apropriação e persiste em reivindicar espaços que são parte de sua vida de bairro. Como foi demonstrado na parte empírica, a população de Belém continua a construir laços de identidade e a fortalecer os sentimentos de pertença com o local, como verificado nos casos da "Rua das Lojas" e da "Festa dos Vizinhos".

\section{Bibliografía}

Ashworth, G.J

1994. "From History to Heritage - From Heritage to Identity: In search of concepts and models". In: Ashworth, G.J \& Larkham, P.J. (Eds.)(1994) - Building a New Heritage: Tourism, Culture and Identity in the New Europe. Londres e Nova Iorque: Routledge.

Brito Henriques, E.

2003. Cultura e Território, das Políticas às Intervenções. Estudo Geográfico do Património Histórico-arquitectónico e da sua Salvaguarda. Tese de Doutoramento em Geografia Humana, Faculdade de Letras da Universidade de Lisboa, Lisboa.

Choay, F.

2001. A Alegoria do Patrimônio. São Paulo: UNESP/Estação da Liberdade.

Custódio, J.

2010. A obra patrimonial da Primeira República (1910-1932). In: 100 Anos do Património. Memória e

Identidade. Portugal 1910-2010. Ed. IGESPAR - Instituto de Gestão do Património Arquitectónico e Arqueológico. Lisboa: IGESPAR, 85-104.

Graham, B., Ashworth, G.J., Tunbridge, J. E.

2000. A Geography of Heritage: Power, Culture and Economy. London: Arnold.

Halbwachs, M.

1990. A memória coletiva. Trad. Laurent L. Schafter. São Paulo: Centauro.

Lobo de Carvalho, J.

2009. Conservação do Património: Políticas de Sustentabilidade Económica. Tese de Doutoramento apresentado ao Instituto Superior Técnico de Lisboa.

Lowenthal, D.

1985. The Past is a Foreign Country. Cambridge: Cambridge University Press.

Lowenthal, D.

1998. The Heritage Crusade and the Spoils of History. Cambridge: Cambridge University Press.

Luchiari, M. T. D.

2005. A reinvenção do patrimônio arquitetônico no consumo das cidades. GEOUSP - Espaço e Tempo, São Paulo, $\mathrm{n}^{\circ} 17$.

Machado, A.

2006. Os espaços públicos da exposição do mundo português e da Expo 98. Lisboa: Editora Parque Expo 98. Mendes, J.A.

2009. Estudos do Património. Museus e Educação. Coimbra: Imprensa da Universidade de Coimbra.

Nora, P.

1993. Entre memória e história: a problemática dos lugares. Trad. Yara Aun Khoury. Projeto história: revista do programa de estudos pós-graduados em história e do departamento de história da PUC-SP, São Paulo, n. 10, 7-28. 
Rose, G.

1995. Place and Identity: A sense of place. In: D. Massey e P. Jess (Eds.), A place in the world? Place, culture and globalization. Oxford: Oxford University Press, 87-132.

Santos, M.

1994. O Retorno do Território. In: SANTOS, M. SOUZA, M. A. A. SILVEIRA, M. L. (org.) Território, Globalização e Fragmentação. São Paulo: HUCITEC.

Santos, M.

2006. A Natureza do Espaço: Técnica e Tempo, Razão e Emoção. $4^{a}$ Ed. São Paulo: Edusp.

Soja, E.

1989. Postmodern Geographies: The Reassertion of Space in Critical Social Theory. London: Verso.

\section{Notas}

1 FERREIRA, Aurélio Buarque de Holanda (1910-1989). Novo Aurélio Século XXI: o dicionário da língua portuguesa. $3^{\mathrm{a}}$ ed. Rio de Janeiro: Nova Fronteira, 1999: 1515; Dicionário da Lingua Portuguesa Contemporânea da Academia das Ciências de Lisboa. Lisboa: Academia das Ciências de Lisboa/Editorial Verbo, 2001: 2784; Houaiss, Antônio (1915-1999) e Mauro Villar (1939-). Dicionário Houaiss da Lingua Portuguesa, 6 vol. Lisboa: Círculo de Leitores, 2002: 2786.

2 Site da UNESCO: http://en.unesco.org

3 O método snowball é uma técnica utilizada por pesquisadores, através do qual os primeiros participantes da pesquisa indicam outros e, assim, sucessivamente, até que se alcance o número estipulado de entrevistados.

4 Entrevistado $\mathrm{n}^{\circ}$ 30, 43 anos, Ator.

$5 \quad$ Entrevistada $n^{\circ} 18,43$ anos, Professora.

6 Entrevistado $\mathrm{n}^{\circ}$ 8, 32 anos, Recepcionista do Mosteiro dos Jerônimos.

$7 \quad$ Entrevistada $n^{\circ} 11,46$ anos, Doméstica.

8 Entrevistado ${ }^{\circ} 26,40$ anos, Engenheiro.

9 Entrevistada n ${ }^{0}$ 6, 66 anos, Proprietária de Ateliê de Costura.

10 Palavras recorrentes utilizadas pelos moradores entrevistados, para definir Belém

11 Entrevistado $\mathrm{n}^{\mathrm{0}} 12,66$ anos, Reformado.

12 Entrevistado $\mathrm{n}^{\circ}$ 30, 43 anos, Ator.

13 Moradores de outras regiões de Lisboa e turistas, que não conhecem o bairro de Belém e, portanto, não tem uma forte ligação com a região. 